\title{
Impact of tuberculosis and long term benefits of anti-retroviral treatment in patients with HIV in Sri Lanka
}

\author{
A H Karunaratne ${ }^{1}$, P M Gamlath ${ }^{1}$, L C Udithani ${ }^{1}$, M S Perera ${ }^{1}$, M T Thashmini ${ }^{1}$, C Sooriyaarachchi ${ }^{1}$, \\ A Wijewickrama ${ }^{1}$
}

(Index words: tuberculosis, long term benefits, ART, HIV, Sri Lanka)

\begin{abstract}
Introduction Although prevalence of HIV infection in Sri Lanka is low, there is a gradual increase in incidence. Effective anti-retroviral treatment (ART) controls the virus, improves immunity and reduces transmission of HIV greatly.
\end{abstract}

Objective We studied the impact of tuberculosis and response to ART in a cohort of patients with HIV in Sri Lanka.

Methodology A retrospective study of all patients with HIV followed up at the ART clinic at National Institute of Infectious Diseases, Angoda, Sri Lanka was carried out. Their socio-demographic data, clinical presentations, anti-retroviral treatment and clinical, immunological and virological response were analysed.

Results Study included 72 patients. Mean age was 47.19 (SD10.354) years. Male to female ratio was 1:0.8. Forty nine $(68 \%)$ patients were diagnosed with HIV after presenting with an opportunistic infection. Of these, 25 had tuberculosis (TB). Another 5 developed TB later. Fifty two $(72.2 \%)$ had CD4 cell counts $<200 / \mu$ l which included

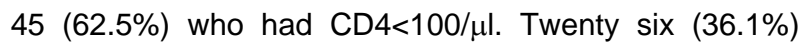
patients were bed ridden and a further 6 (8.3\%) were physically dependent at the time of diagnosis. Mean duration of ART was 82.4 months. With ART, CD4 cell counts and mobility improved. In 38 (52.8\%) CD4 counts increased to more than $500 / \mu \mathrm{l}$. Viral load became undetectable in 62 (86.1\%). Sixty nine (95.8\%) became completely physically independent.

Conclusion TB is a common co-infection in patients with HIV in Sri Lanka. Though many patients with HIV presented with poor immunological and physical status, ART markedly improved these outcomes and reduced the viral load which results in prevention of spread of HIV. Therefore, ART should be supported and encouraged.
Ceylon Medical Journal 2018; 63: 143-148

DOI: http://doi.org/10.4038/cmj.v63i3.8726

\section{Introduction}

Human immunodeficiency virus (HIV) infection is a major global public health problem. At the end of 2016 there were approximately 36.7 million people living with HIV globally and 1.8 million people becoming newly infected in 2016 [1]. In Sri Lanka, in 2016, the estimated number of HIV infected people was around 4000. Though Sri Lanka is a country with low prevalence, the incidence of HIV has been slowly rising [2].

Tuberculosis (TB) is the leading cause of morbidity and mortality in people with HIV worldwide. People living with HIV have a 21-36 times higher risk of developing TB compared to those without HIV [3]. Globally, about 30\% of HIV-infected persons have concomitant TB infection. However, this is usually latent [4]. HIV co-infection is the strongest risk factor for progression from latent $\mathrm{TB}$ to active disease. Similarly, TB itself exacerbates progression of HIV infection [5].

Though prevalence of HIV is low in Sri Lanka, tuberculosis is common. The annual incidence of TB is 9,000-10,000 [6]. The impact of TB on HIV and vice versa has not been assessed in Sri Lanka although there is high prevalence of TB in the country.

Though there is no cure for HIV infection, effective anti-retroviral (ARV) drugs can control the virus. In Sri Lanka ARV drugs were included in the National STD and AIDS Control Program (NSACP) in 2004 and is provided free of charge to people living with HIV. In 2016, WHO recommended providing lifelong ART to all people living with HIV [7].

${ }^{1}$ National Institute of Infectious Diseases, IDH, Angoda.

Correspondence: AW, e-mail: <anandawijewickrama@hotmail.com>. Received 16 July 2018 and revised version accepted 17 July 2018.

This is an open-access article distributed under the terms of the Creative Commons Attribution License, which permits unrestricted use, distribution, and reproduction in any medium, provided the original author and source are credited. 
With the introduction of highly potent ARV drugs, the clinical outcome of HIV infection has improved significantly. This has increased the life-span of people living with HIV to near normal levels [8]. Furthermore, with good adherence to ARV treatment, transmission of HIV would reduce by $96 \%$ [1]. Studies have been conducted in many countries regarding response to AntiRetroviral Treatment (ART) in people living with HIV.

CD4 cell count and viral load are the most commonly measured parameters which assess efficacy of ART [9]. Many studies have shown marked increase in CD4 cell count and marked reduction in viral load with ART [10,11].

Improving immunity and reduced viral load of HIV lead to increased survival of people living with HIV [12,13]. In the United States alone, it had been estimated that at least 3.0 million years of life have been saved among patients with AIDS because of ART [12]. Studies show that people living with HIV who are on ART and have a recent undetectable viral load and CD4 cell counts $>500$ cells $\mu \mathrm{l}$, do not have an increased risk of death compared to the general population [13]. In addition, sustained virological response in people living with HIV would reduce transmission of HIV.

Data from Sri Lanka on the positive immunological and virological responses as well as improvement in quality of life with ART, is useful to enlighten health professionals regarding the usefulness of ART and to convince policy makers to allocate funds for ARV drugs and ART programs. It can also help convince people living with HIV to have ART. This information is very important in Sri Lanka as ART programs have low priority due to low prevalence of HIV in the country.

\section{Methodology}

National Institute of Infectious Diseases (NIID), Angoda, with its in-ward facility for HIV/AIDS patients and its ART clinic, serves as a main centre for HIV care in Sri Lanka. Many patients with HIV/AIDS are referred there from hospitals and clinics across the country. At present, about $12 \%$ of the total number of people living with HIV on ART are followed up at this institute. Patients who were transferred to other ART clinics, patients who died and those who default ART for more than 6 months were excluded from the study.

All HIV patients attending the ART clinic at the National Institute of Infectious Diseases were included in this retrospective study. Their socio-demographic characteristics, clinical and health status at the time of initial enrolment in the clinic and on subsequent visits and complete profile of antiretroviral therapy were documented prospectively. Immunological assessment was done at pre-treatment point and at 3-6 monthly intervals thereafter by measuring CD4 cell count using flow-cytometry. Viral load was assessed at 6-12 month intervals using real time PCR. Both these tests were done at the National Laboratory of the National STD and AIDS Control Program.

Data on immunological and virological response to ART as well as improvement in the physical status were extracted from clinic records. Data was analysed using SPSS version 23.

Ethical clearance was obtained from the Institutional Ethical Review Committee of National Institute of Infectious Diseases, Angoda.

\section{Results}

\section{Patient characteristics}

A total of 72 patients, 40 males and 32 females, were included in the study. Mean age was 47.19 years (SD 10.35). Of the 40 male patients 29 were heterosexual, 4 were homosexual and 6 were bisexual. All 32 female patients were heterosexual. None were intravenous drug abusers (Table 1).

Table 1. Demographic and baseline immunological characteristics of the sample

\begin{tabular}{lll}
\hline Characteristic & Number & $\%$ \\
\hline Age group & & \\
$\quad<40$ years & 18 & 25 \\
$\quad>40$ years & 54 & 75 \\
Gender & & \\
$\quad$ Male & 40 & 55.6 \\
Female & 32 & 44.4 \\
Sexual preference & & \\
Heterosexual & & 84.7 \\
Homosexual & 61 & 5.6 \\
Bisexual & 4 & 8.3 \\
CD4 count & 6 & \\
$\quad<200$ cells $/ \mu 1$ & & 29.2 \\
$\quad>200$ cells $/ \mu 1$ & 51 & \\
\hline
\end{tabular}

Of the 72 patients, 49 (68\%) were diagnosed with HIV when they presented with an opportunistic infection. This is in keeping with the finding that $52(72.2 \%)$ had CD 4 cell counts $<200 / \mu l$ at the time of diagnosis. This included $45(62.5 \%)$ who had CD4 cell count $<100 / \mu$ lat the time of diagnosis. Another 17 (23.6\%) had CD4 counts between

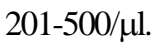

At the time of the study $65(90.3 \%)$ had been on ART for more than 2 years. Another 4 were on ART for a period of 1 to 2 years while 3 had received ART for less than 1 year. Mean duration of ART was 82.4 months (SD 38.8). 


\section{Association with tuberculosis}

Of the 49 presenting with opportunistic infections, 25 had tuberculosis. Five more later developed TB resulting in a total of $30(41.7 \%)$ with $\mathrm{TB}$. At the time TB was diagnosed, CD4 cell counts were below 100 cells $/ \mu 1$ in 16 patients and between 100-200 cells/ $\mu$ in another 6. However, in 3 CD4 was $>700$ cells $/ \mu 1$. Seventeen $(56.7 \%)$ had pulmonary TB, 6 (20.0\%) had TB lymphadenitis and 2 had both pulmonary and lymph node TB. Three $(10.0 \%)$ had TB meningitis. One patient each had pleural and spinal TB (Figure 1). TB was diagnosed by demonstrating alcohol and acid fast bacilli in sputum, lymph node aspirate, pleural fluid or cerebro-spinal fluid in 26, and on radiological appearance in four.

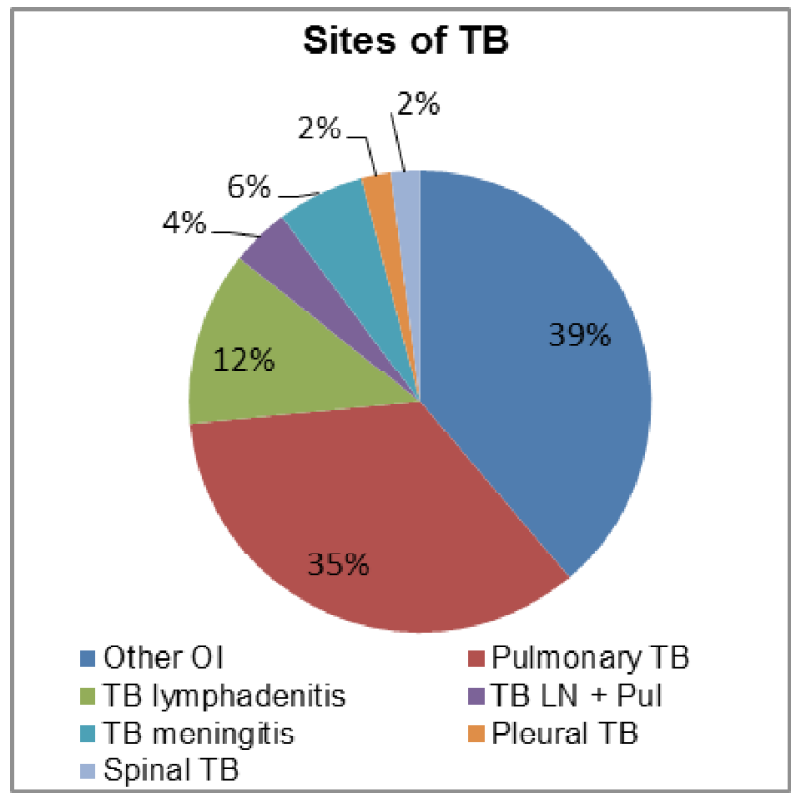

Figure 1.Sites of tuberculosis.

\section{Response to ART}

With ART, patients had marked immunological improvement as reflected by the increase in CD4 counts. At the time of commencement of ART, 45 (62.5\%) had CD4 counts $<100$ cells $/ \mu \mathrm{l}$ while another $7(9.7 \%)$ had CD4 counts between 101-200/ $\mu \mathrm{l}$. By end of 6 months of anti-retroviral treatment, 15 out of $65(23.1 \%)$ had CD 4 count rise of $>0 / \mu \mathrm{l}$. By end of one year 59 out of $72(81.9 \%)$ had CD 4 rise of $>50 / \mu \mathrm{l}$. And this trend continued.

At the time of data collection none of the patients on treatment had CD4 counts $<100 / \mu \mathrm{l}$. However, a majority $(62.5 \%)$ had CD4 $<100 / \mu$ l before commencement of ART. In $38(52.8 \%)$ CD4 counts increased to $>500 / \mu$ (Table 2). This CD4 rise was not associated with gender, age or baseline CD4 count or with co-infection with tuberculosis (Table 3). Mean CD4 rise in response to 12 months of ART in TB-HIV co-infected patients $(222$ cells $/ \mu \mathrm{l})$ was similar to non-TB HIV patients $(232 \mathrm{cell} / \mu \mathrm{l})$.
Figure 2 shows the crude mean increase in CD4 cell count after one year of ART according to the baseline CD4 cell count. On average, after one year of ART, CD4 cell counts had increased by $251.8 / \mu \mathrm{l}(\mathrm{SD}=188.8)$ in patients with baseline CD4 < 100 cells $/ \mu 1$, by $228 / \mu 1$ ( $\mathrm{SD}=159.7$ ) in patients with CD4 between 100 and 199 cells, and by $161.5 / \mu \mathrm{l}(\mathrm{SD}=222.5)$ in those with $\mathrm{CD} 4$ counts $>200$ cells $/ \mu \mathrm{l}$.

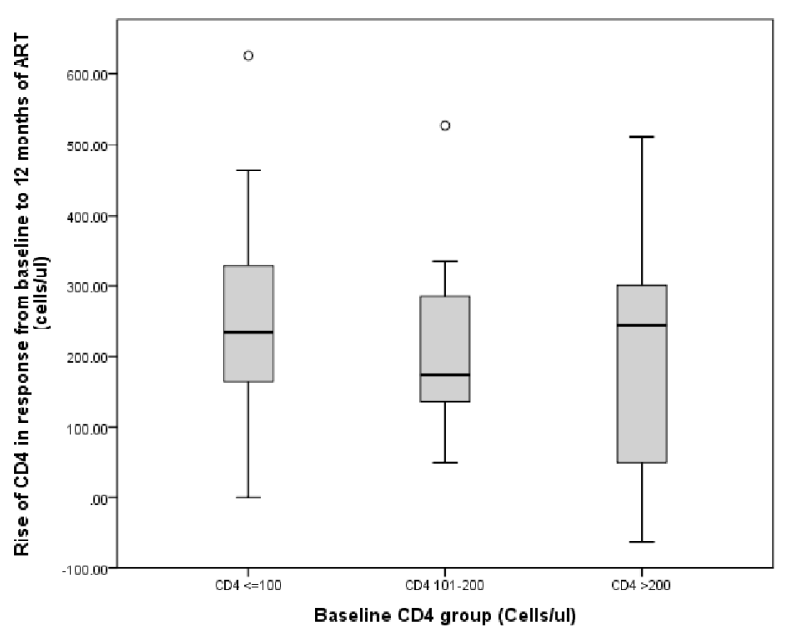

Figure 2. Increase in CD4 cell count after one year of ART according to the baseline CD4 cell count.

Together with the immunological improvement, physical condition of these patients also showed marked improvement. Before commencing on ART, 26 patients $(36.1 \%)$ were bed ridden and further $6(8.3 \%)$ were physically dependent. After ART, 70 patients $(95.8 \%)$ had totally independent physical functioning. Only one patient, who had a stroke, was still bed-ridden. Another, who had tuberculosis of the spinal cord and was unable to walk due to paralysis of her left leg, could walk with support at the time of data collection (Table 2).

Because of improvement in physical condition 49 were employed. Sixteen were housewives. Only seven people living with HIV were unemployed. Thirty one $(43 \%)$ had an average monthly income > Rs.20,000 (Sri Lankan Rupees) per month while another 13 had and average monthly income between Rs.10,000-20,000.

Of the 19 patients who had viral loads assessed after one year of ART (this was done sparingly at that time), 13 $(68.4 \%)$ had undetectable viral loads. However, viral load is measured at 6-12 monthly intervals now to assess response to ART. With ART, viral load had become undetectable $(<34 / \mu \mathrm{l})$ in 62 patients $(86.1 \%)$ and further $7(9.7 \%)$ had a viral load $<1000 / \mu$ l showing effectiveness of ART. 
Table 2. CD4 counts and physical status before starting ART and at final evaluation and viral load at final evaluation

\begin{tabular}{ccc}
\hline Characteristic & Pre ARTNumber (\%) & After ARTNumber (\%) \\
\hline Base line CD4 counts & & $0(0.0)$ \\
$<100$ & $45(62.5)$ & $3(4.2)$ \\
$101-200$ & $7(9.7)$ & $31(43.1)$ \\
$201-500$ & $17(23.6)$ & $20(27.8)$ \\
$501-700$ & $2(2.8)$ & $18(25)$ \\
$>700$ & $1(1.4)$ & \\
Physical ability & & $01(1.4)$ \\
Bed-ridden & $26(36.1)$ & 00 \\
Sitting only & $01(1.4)$ & $01(1.4)$ \\
Walking with support & $05(6.9)$ & $69(95.8)$ \\
Independent & $40(55.6)$ & $72(100)$ \\
Total & $72(100)$ & \\
Viral load (Final evaluation) & & $62(86.1)$ \\
$<34$ copies/ml & & $7(9.7)$ \\
<34-1000 copies/ml & & $2(2.8)$ \\
1000-10000 copies/ml & & $1(1.4)$ \\
\hline
\end{tabular}

Table 3. Association of demographic and immunological factors and TB co-infection with immunological success after one year of ART

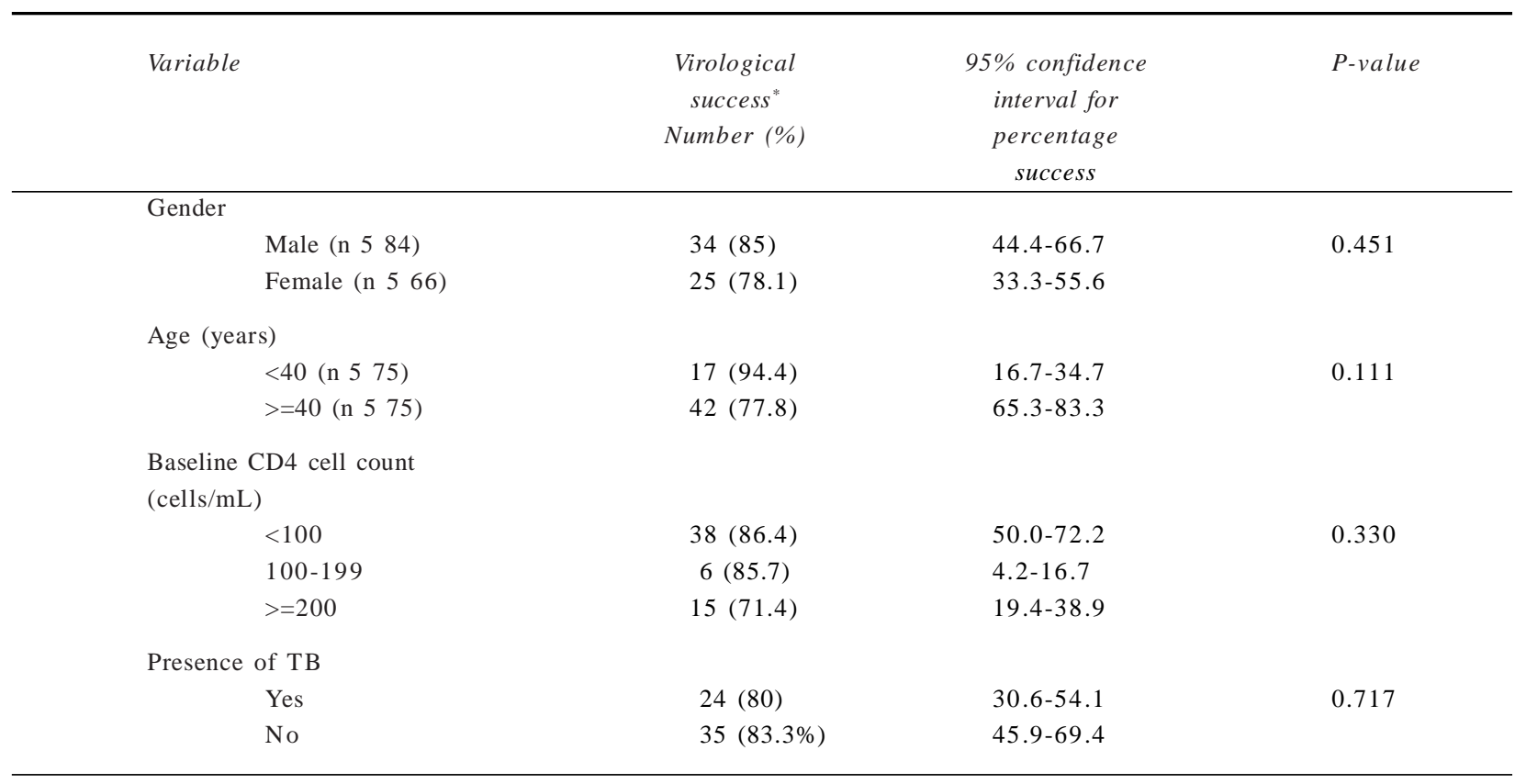

P-values were for chi-square tests.

*Assessed as an increase in the CD4 cell count of at least 50 cells/mL over the baseline values

\section{Discussion}

This study shows a strong correlation between TB and HIV in Sri Lanka. This indicates that TB services should be used as an entry point for the diagnosis of HIV and patients can then be provided ART [5].
As similar relationship is recognized in other countries as well, World Health Organization (WHO) recommends HIV testing in all patients with TB [3]. This is important as TB is common in Sri Lanka. However, in Sri Lanka, guidelines regarding management of tuberculosis still do not recommend 
testing all TB patients for HIV [6]. Our study re-iterates the need for HIV testing in all patients with TB and the need to implement this soon.

Studies done in Western and African countries demonstrate good immunological and virological response to ART. There are only a few such studies done in the Indian sub-continent. Only a few studies have looked at correlation between virological and immunological improvement, physical improvement and economic stability.

Many studies have shown rise of CD4 cell counts indicating good immunological response to ART. In the UK Collaborative HIV Cohort Study (UK CHIC) a marked increase in CD4 cell counts were seen in the first year of ART and this continued to increase up to 5 years on ART. Of these patients $81 \%$ had CD4 cell counts $<350$ cells $/ \mu$ l at commencement of ART whereas $79 \%$ of patients who were on ART for more than 5 years had CD4 cell counts > 350 cells/ $\mu$ l and $52 \%$ had CD4 counts $>500$ cells/ $\mu 1$ [6]. Interestingly in our study too, a similar percentage $(52.8 \%)$ of patients had CD4 cell counts $>500 / \mu \mathrm{l}$ after an average follow up of 6.8 years ART. However, this is despite $62.5 \%$ of patients having a CD4 cell count $<100 / \mu \mathrm{l}$ at the commencement of ART. Our findings show that even patients with severe immune-suppression respond well to ART.

A Japanese study showed that lower CD4 cell counts were associated with poorer physical condition and lower level of activities of daily living in people living with HIV [14]. A South African study showed that ART significantly reduced fatigue levels while increasing the ability to perform normal activities and work. This was associated with steady rise in CD4 cell counts [15]. In our study, there was a marked improvement of initial physical disability with $95.8 \%$ of patients becoming physically independent after ART. This occurred together with improvement of CD4 count. The fact that almost all our patients became physically independent is very important as they are then able to contribute to society. Furthermore, this increases their self-esteem which in turn would improve compliance to ART.

With improvement in physical status, many of our patients started employments. Our finding that 49 people living with HIV were employed and 31 were earning more than 20,000 SLR is notable for a low-middle income country. All those employed were earning more than Rs. 10,000 per month which is more than the recommended minimum wage in the country [13].

Reduction of viral load as a response to ART has been shown in many studies from Africa, America and Europe. In a large study done in Europe, $85 \%$ of patients achieved a reduction of viral load to $<500$ copies $/ \mathrm{ml}$ by 32 weeks of ART [11]. Another study done in Barbados showed that $82 \%$ of patients achieved a reduction of viral load to undetectable levels within 6 months of ART [17].
The difference in the rate of achieving undetectable viral load is probably due to the treatment regime, in addition to factors like treatment compliance [17].

In our study, 13 out of 19 patients, who had the viral load measured at the end of one year of ART, achieved an undetectable viral load by 12 months of treatment and $86.1 \%$ achieved an undetectable viral load in an average of 82.4 months of ART. Similar reduction in viral load was seen in another study done at a different ART clinic in Sri Lanka [18]. The longer duration needed for achieving an undetectable viral load in our patients was probably due to the fact that a large proportion were severely immuno-suppressed with advanced disease at the beginning of treatment. Patients with higher viral loads have an initially slow response to ART [10].

In addition to improving the physical and immunological status of patients, ART markedly reduces HIV transmission from people living with HIV to others. In a study of 1763 sero-discordant couples, early initiation of ART had 93\% lower risk of HIV infection among partners compared to the group without ART. This study showed that successful treatment of HIV is a highly effective method for the prevention of sexual transmission of the virus and the usefulness of ART as a public health strategy to reduce the spread of HIV infection [19,20].

Therefore, ART should be considered as an economically attractive health investment even in countries with limited resources like many Asian countries including Sri Lanka [21]. Use of ART has expanded beyond treatment of HIV infection. ART can virtually eliminate mother to child transmission and will prevent heterosexual transmission [22]. WHO and International Antiviral Society-USA recommends starting ART in all HIV infected individuals with detectable plasma virus with HIV regardless of CD4 cell count or disease stage [7,22].

\section{Conclusions}

This study sample, though relatively small, consisted of a high proportion of patients presenting with opportunistic infections, very low CD4 cell counts and poor physical status. The study demonstrated the importance of co-infection with tuberculosis in HIV, the positive impact of ART has patients with AIDS and value of ART in preventing the transmission of the disease in Sri Lanka. These findings reiterate the usefulness of ART and the need for readily available supply of anti-retroviral medicines for people living with HIV in resource limited countries such as Sri Lanka.

\section{Acknowledgements}

We thank Dr. Jayanthi Elvitigala, Consultant Microbiologist at NSACP for providing services to do CD4 cell counts and viral loads and acknowledge the support of staff of ART clinic of NIID. 


\section{References}

1. HIV/AIDS [Internet]. World Health Organization. 2018 [cited 7 August 2018]. Available from: http://www.who.int/ gho/hiv/en/

2. Annual Report 2016. National STD/AIDS Control Programme, Ministry of Health, Sri Lanka. http://www. aidscontrol.gov.lk/images/pdfs/publications/new-Annualreport-2016-online-version-.pdf

3. A guide to monitoring and evaluation for collaborative $\mathrm{TB} /$ HIV activities: 2015 revision [Internet]. World Health Organization. 2018 [cited 7 August 2018]. Available from: http://www.who.int/tb/publications/monitoring-evaluationcollaborative-tb-hiv/en/

4. Getahun H, Gunneberg C, Granich R, Nunn P. HIV Infection-Associated Tuberculosis: The Epidemiology and the Response. Clin Infect Dis 2010; 50(S3): S201-S7.

5. Pawlowski A, Jansson M, Sköld M, Rottenberg M, Källenius G. Tuberculosis and HIV Co-Infection. PLoS Pathogens 2012; 8(2): e1002464. doi.org/10.1371/journal. ppat. 1002464

6. National Programme for Tuberculosis Control \& Chest Diseases, Sri Lanka [Internet]. Nptccd.health.gov.lk. 2018 [cited 8 August 2018]. Available from: http://www.nptccd. health.gov.lk/a_view_documents.php?id= $5 \&$ category $=3$

7. Consolidated guidelines on the use of antiretroviral drugs for treating and preventing HIV infection [Internet]. World Health Organization. 2018 [cited 8 August 2018]. Available from: http://www.who.int/hiv/pub/arv/arv-2016/en/

8. Suparna PN, Achappa B, Unnikrishnan B, et al. Evaluation of Carotid Atherosclerosis in Patients with HIV-1 Infection. J Clin Diagn Res 2013: 7(2): 261-4.

9. Nash D, Katyal M, Brinkhof M, Keiser O, May M, Hughes $\mathrm{R}$, et al. Long-term immunologic response to antiretroviral therapy in low-income countries: a collaborative analysis of prospective studies. AIDS 2008; 22(17): 2291-302.

10. May M, Gompels M, Delpech V, Porter K, Orkin C, Kegg $\mathrm{S}$, et al. Impact on life expectancy of HIV-1 positive individuals of CD4+ cell count and viral load response to antiretroviral therapy. AIDS 2014; 28(8): 1193-1202.

11. Phillips AN, Staszewski S, Weber R, et al. HIV Viral Load Response to Antiretroviral Therapy According to the Baseline CD4 Cell Count and Viral Load. JAMA 2001; 286(20): 2560 .
12. Walensky RP, Paltiel AD, Losina E, et al. The Survival Benefits of AIDS Treatment in the United States. $J$ Infect Dis 2006; 194: 11-9 11.

13. Rodger A, Lodwick R, Schechter M, et al. Mortality in well controlled HIV in the continuous antiretroviral therapy arms of the SMART and ESPRIT trials compared with the general population. AIDS 2013; 27(6): 973-9.

14. Yamaguchi T, Hashimoto S, Oka S, et al. Physical Condition and Activity of Daily Living among HIV Patients Infected through Blood Products in Japan. J Epidemiol 2002; 12(5): 383-93.

15. Rosen S, Larson B, Rohr J, et al. Effect of antiretroviral therapy on patients' economic well-being: five-year followup. AIDS 2014, 28: 417-24.

16. National minimum wage of workers Act, No. 3 of 2016. Gazette of the Democratic Socialist Republic of Sri Lanka of March 24, 2016. http://www.ilo.org/dyn/natlex/ docs/ ELECTRONIC/103507/125777/F-1209885464/ LKA103507.pdf

17. Kilaru KR, Kumar A, Sippy N, Carter OA, Roach TC. Immunological and virological responses to highly active antiretroviral therapy in a non-clinical trial setting in a developing Caribbean country. HIV Med 2006; 7(2), 99-104.

18. Rajapaksa L, Herath N, Aryaratne KAM, Weerasinghe G. Response to ART among adult PLHIV: a prospective study at HIV clinic, Colombo. Sri Lanka. JoSHH 2016; 2: 20-6.

19. Cohen MS, Chen YQ, McCauley M, et al. Prevention of HIV-1 Infection with Early Antiretroviral Therapy. $N$ Engl J Med 2011; 365: 493-505.

20. Cohen MS, Chen YQ, McCauley M, et al. Antiretroviral Therapy for the Prevention of HIV-1 Transmission. N Engl J Med 2016; 375: 830-9.

21. Goldie SJ, Yazdanpanah Y, Losina E, et al. CostEffectiveness of HIV Treatment in Resource-Poor Settings - The Case of Côte d'Ivoire. N Engl J Med 2006; 355 : 1141-53.

22. Günthard HF, Saag MS, Benson CA, et al. Antiretroviral Drugs for Treatment and Prevention of HIV Infection in Adults. 2016 Recommendations of the International Antiviral Society-USA Panel. JAMA 2016; 316(2): 191-210. 